
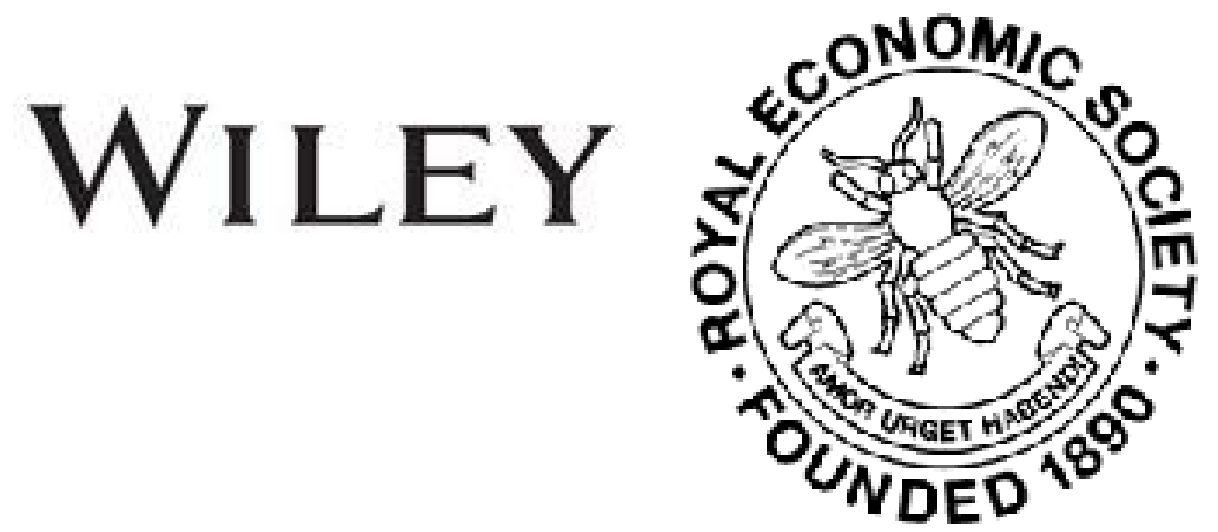

The Equalisation of Rates in London

Author(s): R. A. Bray

Source: The Economic Journal, Vol. 18, No. 70 (Jun., 1908), pp. 231-241

Published by: Wiley on behalf of the Royal Economic Society

Stable URL: http://www.jstor.org/stable/2220702

Accessed: 27-06-2016 07:12 UTC

Your use of the JSTOR archive indicates your acceptance of the Terms \& Conditions of Use, available at

http://about.jstor.org/terms

JSTOR is a not-for-profit service that helps scholars, researchers, and students discover, use, and build upon a wide range of content in a trusted digital archive. We use information technology and tools to increase productivity and facilitate new forms of scholarship. For more information about JSTOR, please contact support@jstor.org.

Wiley, Royal Economic Society are collaborating with JSTOR to digitize, preserve and extend access to The Economic Journal 


\section{THE EQUALISATION OF RATES IN LONDON.}

In the year 1907-8 the rates levied by the different Borough Councils varied from $6 s$. $3 d$. in St. Anne's and St. James's, Westminster, to $10 s$. $8 d$. in Bromley, Poplar. The anomalies become more apparent if we deduct the rate raised in respect of expenditure borne centrally, and consider only the rate which represents expenditure borne locally. This local rate is, in St. Anne's and St. James's, 1s. 2d., and in Bromley 5s. 0d., the rate in the second case being more than four times the rate it is in the first. The amazing difference between the two challenges attention and demands explanation. In considering the matter a little more closely, it is desirable to take not a single year, which may represent an abnormal state of affairs, but the average of four years. I have selected for this purpose the average for the four years 1901-2 to 1904-5, and I have chosen these particular years because the calculations involved have been made by Mr. Harper, the Statistical Officer of the London County Council, in reports submitted to that body. In order to avoid a needless multiplication of figures, I shall confine the discussion to four Boroughs: Poplar and Bermondsey, where the rates are highest; and Paddington and Kensington, where they are lowest. I have excluded the City and Westminster because they can neither be said to present a picture of normal Boroughs.

The average local rate for the four years in each of the Boroughs is :-

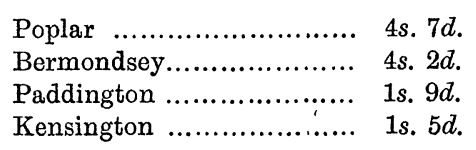

One reason for this disparity may be found in the difference of assessable value per head of population. In a district mainly inhabited by the rich this figure will be high, while in a district mainly inhabited by the poor it will be low. For the four 
Boroughs the assessable value per head is, in pounds, as follows :-

\begin{tabular}{|c|c|}
\hline 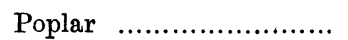 & $4 \cdot 8$ \\
\hline Bermondsey ............. & $7 \cdot 1$ \\
\hline Paddington . & $9 \cdot 8$ \\
\hline Kensington ................... & $12 \cdot 7$ \\
\hline
\end{tabular}

It will be seen that low rates and a high assessable value, and high rates and a low assessable value, go together. This, in general, is true of the other Boroughs. In the eight Boroughs where rates are lowest (excluding the City and Westminster), the average assessable value is $£ 101 s$., while in the eight Boroughs where rates are highest, the average assessable value is $£ 54 s$., little more than half. If the assessable value per head were the same in the four Boroughs, and if that value were the value for Kensington, the local rates would be :-

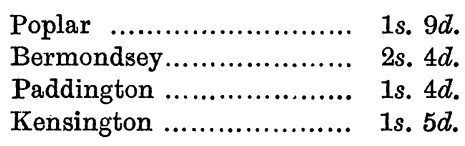

while if that value were the value for Poplar, the figures would be :-

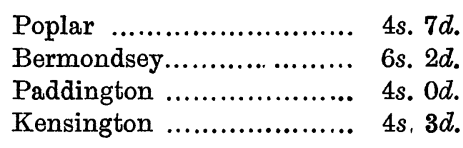

On the assumption of equal assessable value the variation in local rates would, to a great extent, disappear ; difference of local rates is thus associated with a difference of assessable value.

But there are other factors which must be considered. A district with a low assessable value is a district largely inhabited by the poor, and where there are many poor we must expect a larger expenditure to be incurred by the Boards of Guardians than where there are few. The poor rate for the four Boroughs is :-

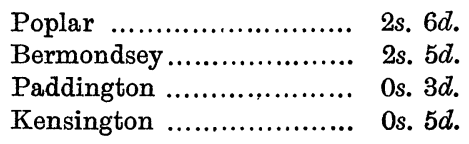

It may be urged that the Poplar and Bermondsey Boards of Guardians are extravagant, especially as regards outdoor relief, and no doubt this is, to some extent, true; but in the famous St.-George's-in-the-East the Guardian rate was $2 s .1 d$., and in Whitechapel 1s. Under any circumstances, therefore, a district 
with a low assessable value must expect to be burdened with a heavy expenditure on the relief of the poor.

The other factor in the local rates is the expenditure of the Borough Councils. For the four districts this was :-

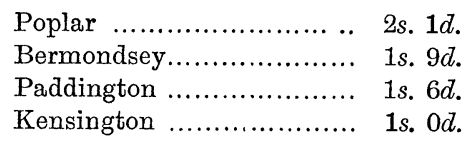

There is here no such striking difference as was found in the case of the Boards of Guardians. But the two rates stand on a different footing; the expenditure of the Guardians benefits only those in receipt of some form of relief, while the expenditure of the Borough Councils benefits all members of the community. Further, while the poor must be provided for somehow, it is possible for Borough Councils to neglect their duties in the way of necessary expenditure without raising a popular outcry. It is, therefore, important to ascertain the Borough Council expenditure per head of population. It might be expected on general considerations that, where the necessary services are effciently carried out, there should not be any great difference between one Borough and another in expenditure per head. For in districts largely inhabited by the poor, the expenditure per head on public health, baths and wash-houses, and the like, would be higher than in wealthy districts, while the opposite would be true of expenditure per head on lighting and streets, and the excess of the one would compensate for the deficiency of the other. The average expenditure of the Borough Councils per head of population for the four years is :-

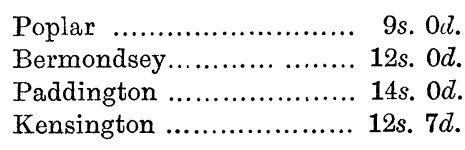

It must be borne in mind that this is the average of the actual expenditure, while the rates are levied to meet expenditure arrived at after the application of certain equalisation funds. Apart from Poplar, the differences are not very large, and in respect of Poplar we should remember that its assessable value per head is very low, and there is, therefore, every inducement to keep down expenditure. This conjunction of low expenditure with a low assessable value, and of high expenditure with a high assessable value, will become more marked if we compare the four districts which have the lowest expenditure with the four 
districts which have the highest, excluding, as before, Westminster and the City :-

\begin{tabular}{|c|c|c|}
\hline & $\begin{array}{l}\text { Expenditure } \\
\text { per head. }\end{array}$ & $\begin{array}{c}\text { Assessable value } \\
\text { per head. }\end{array}$ \\
\hline Deptford & . $4 s .1 d$ & $£ 5 \cdot 5$ \\
\hline Bethnal Green & 4s. $7 d$. & $£ 4 \cdot 1$ \\
\hline Mile End Old Town $\ldots \ldots \ldots \ldots \ldots$ & $5 s .11 d$. & $£ 3 \cdot 8$ \\
\hline Stoke Newington $\quad \ldots \ldots \ldots \ldots \ldots \ldots$ & 6s. $4 d$. & $£ 6.6$ \\
\hline Chelsea...$\ldots \ldots \ldots \ldots \ldots \ldots \ldots \ldots \ldots$ & $14 s .11 d$. & $£ 11 \cdot 5$ \\
\hline Marylebone..$\ldots \ldots \ldots \ldots \ldots \ldots \ldots$ & $17 s .0 d$. & $£ 13 \cdot 3$ \\
\hline Hampstead . & 19s. $5 d$. & $£ 11 \cdot 7$ \\
\hline Holborn & $25 s .5 d$. & $£ 15 \cdot 3$ \\
\hline
\end{tabular}

Now if, as has been shown to be reasonable, there should be no great difference in expenditure per head, it is impossible to resist the conclusion that districts with a low assessable value keep down unduly the cost of the necessary services, while districts with a high assessable value swell the cost by unjustifiable extravagance.

Three conclusions follow from the foregoing examination into the differences of local rating. First, high rates are, in the main, due not to local extravagance, but to low assessment; in other words, the burden of the rates is most heavy where the district is most poverty-stricken. Secondly, another cause for high rates is to be found in the fact that where assessments are low there are many poor and, consequently, large demands for expenditure on the part of Boards of Guardians. Thirdly, the rates in many of these lowly-assessed districts would be yet higher than they actually are if the fear of the rates did not lead to a cutting down of much desirable expenditure on public health, roads, lighting, and the like. The division of London into cities of the poor and cities of the rich injures the poor in three different ways; they stand in greater need of public services, and actually receive less, and what little they receive, measured in rates, costs them more than is the case in better favoured districts. Whether, therefore, we look to the claims of humanity or to the claims of justice, London stands in urgent need of a satisfactory scheme for the equalisation of the rates.

\section{Existing Equalisation Funds.}

Before considering such a scheme, it is desirable to examine the existing regulations which secure a certain amount of equalisation. These are many and very complex and very cumbersome, and it is possible to discuss the question only in the broadest outline, omitting sundry intricacies of detail. 
There is first the Metropolitan Common Poor Fund, administered by the Local Government Board. The cost of certain services carried out by the Guardians, together with the amount of a grant at the rate of $5 d$. a day for each adult indoor pauper, is ascertained, and the several amounts totalled for the whole of London. This total sum is then apportioned among the unions on the basis of rateable value, and is, therefore, equalised. The chief services, whose cost is thus equalised, are the maintenance of lunatics and insane poor, indoor paupers, pauper children, and the provision of the salaries and the rations of officers. The Local Government Board exercises a very strict control over the Guardians. The Board may require the Guardians to appoint such officers as it thinks necessary, and has the power of fixing and approving salaries, and of rejecting and dismissing many of the officers selected by the Guardians. It is this control which has made it possible to centralise a large amount of poor-law expenditure. From the point of view of equalisation, the case of the Guardians is of importance, because it presents an example of an elected body which can draw on central funds because there is the safeguard of central control against extravagance on the one hand, and against inefficiency on the other.

The second method of equalising expenditure is to be found in the County Grants administered by the London County Council. The following are the more important County Grants. There is first the indoor pauper grant of $4 d$. a head per day for every indoor pauper. But this grant, with that whimsical inconsistency characteristic of much legislation, is based on the number of paupers prior to 1888 , and not on the number of paupers in each particular year. During the twenty years that have elapsed much water has flowed under the bridges, and many paupers have surged into some districts and out of others. In consequence, the grant bears no adequate relation to existing requirements. Secondly, the County Council pays half the salaries of medical officers of health and sanitary inspectors appointed by the local authorities. Finally, omitting many small grants, the County Council administers the Equalisation Fund.

The Equalisation Fund consists of a sum equal to the produce of a $6 d$. rate for all London. It is distributed among the different Boroughs in amounts proportional to the population of each Borough. The idea underlying the institution of the fund was the belief that the expenditure of each Borough was proportional to its population. As was shown above, there is a good 
deal to be said for this theory. But while it may be true that the expenditure of each Borough per head ought to be about the same, it does not follow that this "ought" will be fulfilled. Nor has this been the case in practice; Deptford, for example, which has the lowest expenditure per head of any Borough Council, received a grant from the Equalisation Fund equivalent to a $2 d$. rate, and other anomalies exist. In short, a district with a low assessable value per head of population stands to gain largely from the application of this fund, but it does not necessarily follow that the expenditure of the district will be high, for it may be kept unduly low. The fault of the Equalisation Fund lies in the fact that, while it may lower rates in poor districts, it provides no guarantee for the efficiency of the service. To advocate, as is sometimes done, an enlargement of this fund is unwise. For we want to equalise not only rates, but the value derived from the several services.

\section{A SCHEME FOR EqUALISATION.}

Any new scheme for equalising rates must satisfy three coniditions: it must remove the present anomalies by establishing a practically uniform rate for each Borough; it must provide safeguards against extravagance; and it must secure efficiency in the different services. There are at the present time in each district of London two directly elected bodies-the Boards of Guardians and the Borough Councils. Are we to retain these minor bodies, or shall we sweep them away, and transfer their power to the County Council? From the point of view of equalising rates there is much to be said for the plan of destruction, as, with a single spending authority, there would automatically be a single rate. But London is a large place, and it is difficult to imagine that one central body could effectively supervise the affairs of four and a half million persons. Either it would be found necessary to increase the membership of the Council to such an extent that the Council would assume unwieldy dimensions, and develop into a machine with an indefinite output of profuse and irrelevant verbiage, or we should be compelled to establish a hierarchy of officials and a close bureaucracy, a system not in accord with principles of English local government. Neither alternative is satisfactory, and we should lose, in addition, even that small amount of interest in local affairs which now exists, and which could ill be spared.

But if we renounce the idea of a single central authority, 
there is no reason why there should be two minor elected bodies in every district, each levying its own rate. We will assume, therefore, that the Boards of Guardians are abolished, some of their powers being given to the County Council, and the remainder transferred to the Borough Councils. To secure equalisation, these reconstructed Borough Councils must, from a financial standpoint, be placed under the control of some central body, and it is clear that a directly-elected body, like the County Council, is more suitable to exercise the necessary powers than a Government department like the Local Government Board. The problem, therefore, which requires solution turns on the question of how the County Council can control the expenditure of the Borough Councils. If we pass in review the chief duties which will devolve on the Borough Councils, we shall be able to show that the task set up does not present any insuperable difficulties.

Let us begin with the redistribution of the powers of the present Boards of Guardians. The most important and the most difficult duty that now devolves on the Guardians is the determination of the kind of relief suitable to meet the needs of each particular case of distress. To discuss in detail this intricate subject is not possible within the limits of a brief essay, but certain fundamental principles should be clear. We want uniformity throughout London, and at the present time each Board follows its own sweet will, regardless of the policy of others. We can only get uniformity if a single authority is ultimately responsible for the principles which guide those who are concerned with individual decisions. To a large extent this is a technical question; no layman can decide whether a patient should be admitted to the infirmary, sent to an asylum or institution for imbeciles, or whether he can be treated in his own home; it is essentially a question for the expert. Are the circumstances really different when we are called on to determine whether a family shall be sent to the workhouse, or receive out-relief; whether a widow shall be assisted to keep her children, or whether some or all of them shall be brought up in an institution? Surely the knowledge and the experience of an expert are as necessary here, as they are recognised to be in cases requiring medical treatment. At the present time we have a chaos of varying policies. Further, not only does one Board of Guardians differ in its administrative principles from another, but even in the same Board the several relief committees are usually at variance, while the same relief committee varies its action with the presence or absence of some particular member. We cannot secure any sort of uniformity 
unless the decisions rest with officers acting under regulations laid down by a central authority. Some way of associating certain members of the Borough Councils with the work of the officials could easily be devised, but practically it would be the expert who would determine the kind of relief that would best meet the needs of any particular family.

Officials under central control will, therefore, determine into which of a number of classes each applicant shall be placed. If the case is one for out-relief the amount will be settled and the cost thrown on the county rate. It may, however, be that admission to an institution is the appropriate treatment. The institutions are, at the present time, under the control of three different bodies. The County Council provides the asylums, and the expenditure for the maintenance of the patients is equalised in a complicated fashion, which need not trouble us. Under the proposed scheme the whole cost will be met directly out of the county rate. The Metropolitan Asylums Board manages the fever hospitals and institutions for imbeciles. This body consists of representatives from the Boards of Guardians and nominees of the Local Government Board. With the disappearance of the Guardians it will likewise cease to exist, and its work will be merged in the work of the County Council. The workhouses and infirmaries are now provided and maintained by the Guardians. The cost of the maintenance of inmates is, to a very large extent, equalised with the help of the Common Poor Fund administered by the Local Government Board, though the loan charges fall on the individual localities. Equalisation here presents no difficulties; the control exercised by the Local Government Board over all expenditure met out of the Common Poor Fund is complete, and would be transferred to the County Councils. The Borough Councils would act as Visiting Committees, performing very much the same duties as are now carried out by the Guardians, though it would be desirable that all contracts should be under the supervision of the County Council. There remain the loan charges. As, under the proposed scheme, the Council, through its officers, would determine the destination of each patient, the buildings would be transferred to the Council, who, for the future, would be responsible for the loan charges, and would provide any new institutions that were required. The children's institutions would pass to the Council as the Education Authority. The sundry minor powers, such as vaccination, now exercised by the Guardians, would be transferred to the County Council, and equalisation, where it does not now exist, could easily 
be secured. In this way the whole of the rate for the relief of the poor will be equalised, and at the same time adequate safeguards provided for efficient administration.

The existing powers of the Borough Councils would not require much change, though they would be placed under the financial control of the County Council. It would, however, be necessary to take from them their right of power of promoting and opposing Bills in Parliament. This power has in the past involved much needless expense, and has frequently led to the not very edifying spectacle of one authority fighting another. Another power which it would be necessary to take from them is the power they have as the valuation authority. A uniform rate for London is uniform only in name so long as the principles of making the assessment vary from district to district. It is essential that the County Council should become the authority for making the valuations for the whole of London.

It will be desirable to show in what way the County Council could exercise financial control. All expenditure must be sanctioned before it is incurred. Every year the Borough Councils would be obliged to submit an estimate to meet the expenses of the coming year, and this estimate would require to be passed by the County Council. It is not as difficult to exercise financial control as is sometimes imagined. The Local Government Board has exercised control of the most minute kind over all the services whose cost is thrown on the Common Poor Fund, and the work of the Borough Councils is not of so disparate a character that central supervision would be impossible. Take, for example, the most costly of the services of the Borough Councils-public health and streets. These are together responsible for more than half the rates. The County Council would find it easy, drawing on the experience of the past, to fix the numbers and the salaries of inspectors and medical officers of health; nor would it be difficult to estimate the cost of maintaining the streets. Such supervision would prevent the cutting down of the necessary expenditure in poor parts, and the extravagance in the wealthy districts, and this, as has already been shown, is certainly necessary. A scale of expenditure for other services could likewise be formed. So far as regards remunerative services, such as " housing" or electric lighting, the latter would naturally pass to the central authority, while the former could be carried out by the local body under conditions laid down by the central.

It has sometimes been urged that an elected body, without full control of its finances, would constitute an anomaly in local 
government, and would not offer responsibilities and attractions sufficient to secure the services of capable persons. There is, however, no reason to believe that under the restrictions proposed we should get candidates inferior to those who now present themselves for election. It is usually forgotten that local government is founded on central control. The Education Authority, for example, cannot build a new school without the consent of the Board of Education, while the receipt of the annual grant depends on compliance with conditions laid down by that body. Further, the Guardians are pre-eminently an instance of an elected board controlled, down to the minutest detail, in all expenditure charged on the Common Poor Fund, and subject to close supervision in their general administration. Nor is it suggested that the reconstructed Borough Council should be deprived of all liberty to spend money without the previous consent of the County Council ; but such expenditure would be a charge on the local, and not on the central, rate. As a matter of fact, with the extra duties assigned to them, the Borough Councils would become more important bodies than they are at present.

The object of this article has been to demonstrate the need and the possibility of a practically complete equalisation of rates; I have not been concerned to show the many economies and the increased efficiency in the various services which would be the result of the proposed reorganisation of London Government. But there is one question so germane to the present discussion that it cannot be dismissed without mention. Is the area of administrative London to remain confined within the existing limits, or shall the borders be extended?

Equalisation of rates has been proved necessary in London because London is split up into cities of the poor and cities of the rich. But this process of segregation has not ended at the borders, and, outside, the same forces are at work, and are producing effects even more disastrous. East Ham and West Ham, Tottenham and Edmonton and Walthamstow are groaning under a burden of rates as heavy as exist in any London borough. Further, since no equalisation funds or common poor fund lessen the burden, they are driven to many undesirable economies. Clearly, such districts must be taken into London, and if we do this we must evidently go further. For these districts will prove a heavy expense, inasmuch as they have been permitted to spring up without proper control over their growth, and usually in the absence of suitable building regulations. We must not, therefore, rest content with receiving into London any district after it 
has advanced far on the road of administrative bankruptcy; we must anticipate the inevitable expansion of the metropolis, and supervise its development. We cannot do this with any hope of success unless we extend the border of London until it includes the whole of the Metropolitan Police area-in other words, until Administrative London and Greater London become conterminous. There will be a central authority for the total area, and in each district a local body, subject to central control, in accordance with the principles already outlined; and there will be a single rate for the whole. The inclusion of the new district would from the point of view of rates make little difference to London. An equalised rate for the year 1905-6 for the administrative county of London would amount to $7 s .5 d$., and for the whole of Greater London $7 s .6 d$., an increase of only a penny. This scheme of expansion doubtless involves large changes, but it is only by a bold policy of this character that we can hope to make out of this huge aggregation of isolated peoples a city adequate to the demands of civilisation and worthy of the Empire of which it is the capital and the heart.

R. A. Bray 